Hudders, L., Van Reijmersdal, E., \& Poels, K. (2019). Editorial: Digital advertising and consumer empowerment. Cyberpsychology: Journal of Psychosocial Research on Cyberspace, 13(2). https://dx.doi.org/10.5817/CP2019-2-xx

\title{
Digital Advertising and Consumer Empowerment
}

\author{
Editorial \\ Liselot Hudders ${ }^{1}$, Eva A. van Reijmersdal2 ${ }^{2}$ \& Karolien Poels ${ }^{3}$ \\ 1 Department of Communication Sciences and Department of Marketing, Ghent University, Belgium \\ ${ }^{2}$ Amsterdam School of Communication Science ASCoR, University of Amsterdam, The Netherlands \\ ${ }^{3}$ Department of Communication Studies, University of Antwerp, Belgium
}

\section{Growth and Success of the Digital Advertising Industry}

The Internet is everywhere, giving people the opportunity to be online from the moment they wake up until they go to sleep. People are strongly tied to digital media such as tablets, laptops, and their smartphones in particular. They are checking them multiple times a day, mainly because they offer them unlimited opportunities to keep them occupied and fulfill several needs (e.g., chatting with friends, checking emails and other personal messages, playing games, reading the news, or browsing random messages through social media). As a consequence, advertisers are now able to reach consumers throughout the day with a wide range of (new) advertising formats. The digital advertising industry has seen an enormous growth in recent years. A growth that is still not at its saturation. Especially mobile ad spending has known a steep increase in recent years. In the United States, digital advertising spending is even expected to exceed traditional ad spending for the first time in 2019 (eMarketer, 2019). Digital advertising provides marketers with an excellent opportunity to interact with consumers and build close relationships with them. In addition, the digital advertising tactics may bypass consumer resistance and scepticism by giving the consumer an active role in the advertising process. The consumer is no longer a passive receiver of advertising content, but an active distributor (by sharing ad content with friends and acquaintances), contributor (by publicly commenting on ad content) and even creator (by (co-)creating ad content for advertisers) of this content. For instance, social media influencers are now producing advertising content and distributing this content among their followers (e.g., De Veirman, Hudders, \& Cauberghe, 2017). Furthermore, digital advertising is often integrated seamlessly with editorial or user-generated content making it harder and more effortful to detect the commercial nature of a message and take deliberate action (such as avoiding or refuting the message). Research on the impact and effects of digital advertising is growing, which is reflected in a substantial and increasing number of (special issues in) academic journals and academic conferences that are fully devoted to digital advertising. The current special issue follows this trend and sheds light on the (active) role of the consumer in the digital advertising process. Moreover, the role of empowerment is stressed. How can consumers, and in particular young consumers, be armed to deal with commercial messages in online environments, which often require other or more advanced processing skills than traditional advertising? Before providing an insight into the studies that are included in this special issue, we discuss the specifics of digital advertising that may provide further guidance for future research in this domain.

\section{Specifics of Digital Advertising}

Digital advertising can be broadly defined as all "brand-initiated communication with the intent to have an impact on people" that occurs through digital media channels (Dahlen \& Rosengren, 2016). Due to its unique characteristics, digital advertising has become an important and indispensable chain in the advertising process. 
Various new advertising formats have arisen that are better able to get the message at the right place at the right target group through tailoring, to get around consumer irritation and avoidance through integration with other content (both editorial and user-generated) and interactively engaging the consumer through liking, sharing, commenting and other direct action links. Last but not least, due to its targeting possibilities and (partly) measurable impact, digital advertising is more cost efficient compared to traditional mass media advertising.

\section{Digital Advertising Can Be Tailored to the Customer}

Advertisers can now easily collect or get access to a large amount of personal and context data from consumers (e.g., by the use cookies, location tracking) that they can use to target their advertising messages. Consequently, advertising messages may be more relevant to consumers (e.g., pop-up message on their mobile phone with a promotional offer for a store they pass by), which may increase their effectiveness. Accordingly, due to very detailed consumer data, digital advertising offers advertisers the possibility of reaching their target groups (even very narrow groups) very efficiently and effectively. For instance, a recent study of Higgins and colleagues (2018) shows that a personalized advertising message on social media (congruent with the target group according to age and gender) led to a higher click-through rate compared to non-personalized advertising. More insights are however needed to examine how people respond to specific types of targeted advertising (e.g., explicit data requests vs. implicit data collection by using cookies) and data collection for commercial purposes (e.g., impact of customers' privacy concern) (for an excellent literature review and future research agenda on online behavioral advertising see Boerman, Kruikemeier, \& Zuiderveen Borgesius (2017)). Furthermore, it should be examined to what extent digital advertising serves less tangible and more long term advertising outcomes, such as brand image and reputation.

\section{Digital Advertising Often Disguises Its Commercial Intent}

Advertising messages are often fully integrated into the media content (e.g., brands promoted by artists in a music video on YouTube or in a game, or brand promotions in the form of news articles on a newspaper site) which may prevent consumers to activate their advertising literacy (all knowledge and skills needed to critically reflect on advertising, Hudders et al., 2017) and make them more vulnerable for subconscious persuasion.

Additionally, consumers are stimulated to interactively engage with the commercial content and the exposure time is often longer compared to traditional television commercials. For instance, advergames engage a player with a brand for several minutes, they are cognitively demanding making sure the player is not distracted by other things (as is often the case with traditional advertising) and they often arouse positive emotions (e.g., going to a next level). Additionally, players often need the product, brand or brand character to play the game (e.g., shaking a bottle of a soda brand to be able to jump as far as possible) making them rely on this product and feeling grateful to this brand when they are able to win the game. These features may make advergames much more persuasive compared to traditional advertising formats, such as the television commercial, especially among a young audience (Hudders, Cauberghe, \& Panic, 2016).

On the other hand, the interactive nature is reflected in the fact that consumers can now interact with the brand directly. They can respond to social media advertisements by liking the post or commenting on it. Especially Instagram stories offer numerous opportunities to interact with the consumer by asking them questions, organizing a poll, etc. This may decrease the distance a consumer feels to a brand. In line with this, digital advertising also offers marketers the opportunity to decrease the gap between advertising exposure and purchase. For instance, many social media advertisements add a link to the web shop enabling consumers to purchase the product in one click. As such, Instagram stories only require one swipe-up to purchase the product. This may lead to more impulsive spending tendencies among consumers and higher sales effects of digital advertisements. A study of Xiang and colleagues (2016) on image-sharing social commerce platforms already showed that the perceived enjoyment of using the platform and its perceived usefulness can increase social media users' urge to buy impulsively, and that their felt intimacy with other users of the platform can increase their impulsive buying tendency. However, research on the specific interactive advertising formats and effects of interactive engagement with the advertiser is still limited. In particular, more research is needed on topics such as mobile advertising, influencer marketing, virtual and augmented reality, artificial intelligence and chat bots, etc. 


\section{Digital Advertising Actively Involves the Consumer}

Third, in the digital advertising environment, consumers are no longer passive recipients of advertising messages but have become an important chain in the advertising process (Erz \& Heeris Christensen, 2018). They are not only important distributers of advertising messages spread through social media, but they also became content creators. As such, influential social media users with a wide reach and expertise in a particular domain (e.g., fashion, food, technology) are thrown into gear to develop advertising messages and spread them amongst their follower base to convince them to like and buy the particular brand. This influencer marketing has become extremely popular the past few years and influencers are used to promote a wide range of products, services and events. For instance, a recent study showed that social media influencers who were promoting unhealthy foods (vs. non-food products) among young children increased overall intake of kilocalories and intake of unhealthy snacks (Coates et al., 2019). However, research on how these (co-)created commercial content affects individuals (e.g., Thompson \& Malaviya, 2013) and how digital advertising can stimulate consumer engagement (e.g., Gavilanes, Flatten, \& Brettel, 2018) is still limited.

\section{Digital Advertising Can be Used to Reach Young Target Groups}

Minors in particular show strong engagement with digital media and spend many hours online (e.g., interacting on social media and playing games). These young consumers are an important target group for advertisers as they often already have their own spending power, have an important impact on the purchases of others (friends, family) and their preferences develop into habits in future years. Accordingly, digital advertising formats are often used to target these young consumers. However, a study of Tanyel, Stuart, and Griffin (2013) among Millenials (born between 1980 and 2000) revealed that their attitudes toward internet advertising were more negative compared to traditional advertising (television, out-of-home and print advertising). Additionally, a study of Zarouali, Ponnet, Walrave, and Poels (2017) among young adolescents (aged 16 to 18) shows that adolescents with a high privacy concern are more sceptical towards retargeted advertising. Although academic research on how this target group responds to digital advertising is growing, much more research needs to be done. Current research on how digital advertising affects minors mainly focuses on children between 7 and 12 years (e.g., De Pauw, De Wolf, Cauberghe, \& Hudders, 2018; Rozendaal, Buijs, \& Van Reijmersdal, 2016), while research on toddlers (for an exception see Nelson, Atkinson, Rademacher, \& Ahn, 2017) and adolescents (e.g., Van Reijmersdal, Boerman, Buijzen, \& Rozendaal, 2017) is still limited.

\section{Ethical Considerations in Digital Advertising}

The growing importance and persuasiveness of digital advertising is also reflected in the increasing number of initiatives from public policy makers, the advertising industry and pressure groups to regulate digital advertising and better protect the consumer. Accordingly, many discussions arise concerning the proper disclosure of digital advertising and the transparent and ethical use of the different advertising tactics to avoid deceit (e.g., Boerman, Helberger, Van Noort, \& Hoofnagle, 2018). For instance, different European countries are currently developing a (self-) regulatory framework to regulate influencer marketing. Discussions arise concerning whether and when influencer marketing can be considered as advertising, how it should be disclosed and which arguments can be used by the influencers to promote the brands on their social media profiles (e.g., EASA, 2019). Similarly, there are concerns about the use of personal data to target and personalize digital advertising. Consumers are often unaware of the use of their data which poses threats to their privacy (Boerman et al., 2017).

\section{Contents in the Current Special Issue}

This issue provides a diverse set of studies that highlight various aspects of digital advertising and how these relate to consumer empowerment. The studies enhance our knowledge of the impact of digital advertising on consumers, the underlying mechanisms that explain digital advertising effects and the boundary conditions for these effects. The focus is not only on adults, but also on how current minors as the new generation respond to, and understand, digital advertising. The studies focus on the three important characteristics of digital advertising as identified above: targeting and personalized advertising, the embeddedness of digital advertising into entertainment, and user-generated content (i.e., reviews). 
First, digital advertising offers unique opportunities to target content. Online a plethora of digital data are recorded and these can easily be used by advertisers to target and personalize their advertising. The idea is that targeted advertising reaches specific target groups that are relevant for the advertiser, thereby, reducing waste of advertising money. In addition, digital data are used to personalize digital advertising, so advertisements become more personally relevant, attractive and therefore, more persuasive. However, the question arises, to what extent consumers have control over their personal data and their privacy. The article by Strychartz, Van Noort, Smit, and Helberger (2019) examines whether providing consumers with technical information on the personalization process can empower them to more critically cope with personalized advertising (and opt-out for the service). In an online experiment $(N=514)$, one group of respondents was exposed to an animated video with voice-over giving them technical knowledge about the personalization processes used by Google, while the other group saw a general informational video about personalization online without technical information. These data were complemented with tracking data of these respondents to record their actual opt-out behaviors. The results of this study showed only an indirect effect of obtaining technical knowledge about personalization on actual optout behavior through perceived severity and motivation to opt-out. Surprisingly, technical knowledge led to decreased perceptions of severity of data collection online for personalization purposes and consequently, to a lowered motivation to opt-out and eventually to a lower actual opt-out. Accordingly, their study suggests that providing people with detailed technical information about personalization may lower their willingness to take action to protect their data and opt-out from the services. They explain this by stating that those consumers are better aware of the risks they face and they may go in a fear control process where they deny the risk.

Second, digital advertising is often embedded into entertaining content. For example brands are integrated in games, YouTuber video's or Instagram posts. As these forms of digital advertising are masked as being entertaining and non-commercial, consumers may find it hard to recognize digital embedded advertising. Especially, minors have less knowledge about persuasion and advertising (i.e. lower advertising literacy levels) than adults and are therefore, expected to have more difficulty in understanding digital embedded advertising. The study by Van Dam and Van Reijmersdal (2019) sheds light on the level of advertising literacy of adolescents regarding embedded advertising in online videos created by social media influencers. They demonstrate that minors are accepting of this kind of advertising, but do not show critical reflections. The study also examines adolescents' response to disclosures of sponsorship, which can be used as a tool to empower audiences by informing them of the persuasive nature of sponsored videos.

The study by De Jans, Hudders, Herrewijn, Van Geit, and Cauberghe (2019) examines another tool to empower minors: they focus on the effectiveness of a digital game-based learning tool to strengthen minors' advertising literacy of digital advertising formats. They conducted an experimental study in which they examine whether a serious mini-game platform that aims to increase teenagers' knowledge and skills related to advertising can actually help them critically cope with advertising and whether this digital tool is more effective compared to a traditional information booklet. The results of an experimental study among 211 adolescents between 10 and 16 years show that both types of interventions (compared to no intervention) increased adolescents' confidence in their knowledge about various advertising tactics, which further increases their motivation to critically reflect on advertising. The game was better able to activate a state of flow compared to the informational booklet, which in turn led to higher enjoyment of the experience and to higher perceived learning. This higher perceived learning in turn led to higher motivation to critically reflect on advertising and higher motivation to interact with the learning materials.

Third, in the digital world, consumers are not only passive receivers of content, but they actively interact with content and even produce their own content. For example, consumers post pictures with their favorite brands, they talk about brands on social media fan pages and they write reviews. The article by Lee and Park (2019) examines how writing online reviews can empower consumers. They use the consumer empowerment framework of Kucuk (2009), distinguishing four types of consumer empowerment in the digital environment: economic, technological, legal and social power. They conducted an extensive and comprehensive discourse analysis on a total of 400 online product reviews published either on a popular review platform in the U.S. or a platform in South Korea. This enabled them to examine differences in consumer empowerment between the two countries, which vary greatly on the individualism-collectivism dimension. Results show that different facets of consumer power were revealed in reviews published in the U.S. versus South Korea. In particular, economic power was most frequently observed in South Korean reviews, while economic, technologic and social power (compared to legal power) more frequently appeared in U.S. reviews. Additionally, reviews in both countries mostly contained 
transformational messages, focusing on emotional experiences customers had with the product. While informational messages (containing objective product information) were dominantly used to express technologic, legal and economic power, transformational messages were merely used to express social power.

The studies in this special issue have important implications for theories on digital advertising and consumer empowerment. In addition, the studies offer implications for both digital advertising practices, but also for empowering both adults and minors with respect to digital advertising.

To conclude, we hope that you enjoy reading the articles in this special issue and that they are inspiring for your own research or teaching and for discussions on the topics of Digital Advertising and Consumer Empowerment. We really enjoyed guest-editing this special issue. This issue would not have been possible without its contributors. Therefore, we want to thank the authors who submitted their work to our special issue and the reviewers who really helped in further improving the quality of the submitted papers. And last but not least, we are grateful to everyone from Cyberpsychology who supported us in the very exciting and interesting process of creating this special issue.

Liselot Hudders, Eva A. van Reijmersdal, and Karolien Poels, guest-editors.

\section{References}

Boerman, S. C., Kruikemeier, S., \& Zuiderveen Borgesius, F.J. (2017). Online behavioral advertising: A literature review and research agenda. Journal of Advertising, 46, 363-376.

http://dx.doi.org/10.1080/00913367.2017.1339368

Boerman, S. C., Helberger, N., Van Noort, G., \& Hoofnagle, C. J. (2018). Sponsored blog content: What do the regulations say? And what do bloggers say? Journal of Intellectual Property, Information Technology and Electronic Commerce Law, 9, 146-159.

Coates, A. E., MPhil, C. A., Hardman, Halford, J. C. G., Christiansen, P., \& Boyland, E. J. (2019). Social media influencer marketing and children's food intake: A randomized trial. Pediatrics, 143(4), e20182554.

http://doi.org/10.1542/peds.2018-2554

Dahlen, M., \& Rosengren, S. (2016). If advertising won't die, what will it be? Toward a working definition of advertising. Journal of Advertising, 45, 334-345. http://doi.org/10.1080/00913367.2016.1172387

De Jans. S., Hudders, L., Herrewijn, L., Van Geit, K., \& Cauberghe, V. (2019). Serious games going beyond the Call of Duty: Impact of an advertising literacy mini-game platform on adolescents' motivational outcomes through user experiences and learning outcomes. Cyberpsychology: Journal of Psychosocial Research on Cyberspace, 13(2), article 3. http://dx.doi.org/10.5817/CP2019-2-3

De Pauw, P., De Wolf, R., Cauberghe, V., \& Hudders, L. (2018). From persuasive messages to tactics: Exploring children's knowledge and judgment of new advertising formats. New Media and Society, 20, 2604-2628.

http://doi.org/10.1177/1461444817728425

De Veirman, M., Hudders, L., \& Cauberghe, V. (2017). Marketing through Instagram Influencers: The Impact of Number of Followers and Product Divergence on Brand Attitude. International Journal of Advertising, 36, 798-828. http://dx.doi.org/10.1080/02650487.2017.1348035

EASA (2019). EASA best practice recommendation on influencer marketing. Retrieved from: http://www.easaalliance.org/sites/default/files/EASA_BEST\%20PRACTICE\%20RECOMMENDATION\%200N\%20INFLUENCER\%20MA RKETING\%20GUIDANCE.pdf 
eMarketer Editors (2019). US digital ad spending will surpass traditional in 2019. EMarketer. Retrieved from: https://www.emarketer.com/content/us-digital-ad-spending-will-surpass-traditional-in-2019.

Erz, A., \& Heeris Christensen, A. (2018). Transforming consumers into brands: Tracing Transformation Processes of the Practice of Blogging. Journal of Interactive Marketing, 43, 69-82.

https://doi.org/10.1016/j.intmar.2017.12.002

Gavilanes, J. M., Flatten, T. C., \& Brettel, M. (2018). Content strategies for digital consumer engagement in social networks: Why advertising is an antecedent of engagement. Journal of Advertising, 47, 4-23.

http://doi.org/10.1080/00913367.2017.1405751

Higgins, S. F., Mulvenna, M. D., Bond, R. B., McCartan, A., Gallagher, S., \& Quinn, D. (2018). Multivariate testing confirms the effect of age-gender congruence on click-through rates from online social network digital advertisements. Cyberpsychology, Behavior, and Social Networking, 21. https://doi.org/10.1089/cyber.2018.0197

Hudders, L., De Pauw, P., Cauberghe, V., Panic, K., Zarouali, B., \& Rozendaal, E. (2017). Shedding new light on how advertising literacy can affect children's processing of embedded advertising formats: A future research agenda. Journal of Advertising, 46, 333-349. http://dx.doi.org/10.1080/00913367.2016.1269303

Hudders, L., Cauberghe, V., \& Panic, K. (2016). How advertising literacy training affect children's responses to television commercials versus advergames. International Journal of Advertising, 35, 909-931.

http://dx.doi.org/10.1080/02650487.2015.1090045

Kucuk, S.U. (2009). Consumer empowerment model: From unspeakable to undeniable. Direct Marketing: An International Journal, 3, 327-342. http://doi.org/10.1108/17505930911000892

Nelson, M. R., Atkinson, L., Rademacher, M. A., \& Ahn, R. (2017). How media and family build children's persuasion knowledge. Journal of Current Issues \& Research in Advertising, 38, 165-183.

http://doi.org/10.1080/10641734.2017.1291383

Park, H., \& Lee, J. (2019). Discourse analysis of online product reviews: A discussion of digital consumerism and culture. Cyberpsychology: Journal of Psychosocial Research on Cyberspace, 13(2), article 4.

http://dx.doi.org/10.5817/CP2019-2-4

Rozendaal, E., Buijs, L., \& Van Reijmersdal, E. (2016). Strengthening children's advertising defenses: The effects of forewarning of commercial and manipulative content. Frontiers in Psychology, 7, article 1186.

http://doi.org/10.3389/fpsyg.2016.01186

Strycharz, J., Van Noort, G., Smith, E., \& Helberger, N. (2019). Turning personalization off: Consumer protection against personalized ads online. Cyberpsychology: Journal of Psychosocial Research on Cyberspace, 13(2), article 1. http://dx.doi.org/10.5817/CP2019-2-1

Tanyel, F., Stuart, E. W., \& Griffin, J. (2013). Have "millennials" embraced digital advertising as they have embraced digital media? Journal of Promotion Management, 19, 652-673. https://doi.org/10.1080/10496491.2013.829161

Thompson, D. V., \& Malaviya, P. (2013). Consumer-generated ads: Does awareness of advertising co-creation help or hurt persuasion? Journal of Marketing, 77(3). https://doi.org/10.1509/jm.11.0403

Van Dam, S., Van Reijmersdal E. A. (2019). Insights in adolescents' persuasion knowledge, perceptions and responses regarding online sponsored videos. Cyberpsychology: Journal of Psychosocial Research on Cyberspace, 13(2), article 2. http://dx.doi.org/10.5817/CP2019-2-2

Van Reijmersdal, E. A., Boerman, S. C., Buijzen, M., \& Rozendaal, E. (2017). This is advertising! Effects of disclosing television brand placement on adolescents. Journal of Youth and Adolescence, 46, 328-342.

http://doi.org/10.1007/s10964-016-0493-3 
Xiang, L., Zheng, X., Lee, M. K. O., \& Zhao, D. (2016). Exploring consumers' impulse buying behavior on social commerce platform: The role of parasocial interaction. International Journal of Information Management, 36, 333347. http://dx.doi.org/10.1016/j.jinfomgt.2015.11.002

Zarouali, B., Ponnet, K., Walrave, M., \& Poels, K. (2017). Do you like cookies? Adolescents' skeptical processing of retargeted Facebook-ads and the moderating role of privacy concern and a textual debriefing. Computers in Human Behavior, 69, 157-165. http://dx.doi.org/10.1016/j.chb.2016.11.050

\section{Issue Content}

\section{Editorial}

Editorial: Digital advertising and consumer empowerment Liselot Hudders, Eva A. van Reijmersdal, and Karolien Poels https://dx.doi.org/10.5817/CP2019-2-xx

\section{Articles}

Article 1:

Turning personalization off: Consumer protection against personalized ads online Joanna Strycharz, Guda van Noort, Edith Smith, and Natali Helberger http://dx.doi.org/10.5817/CP2019-2-1

Article 2:

Insights in adolescents' persuasion knowledge, perceptions and responses regarding online sponsored videos

Sophia van Dam and Eva A. van Reijmersdal

https://doi.org/10.5817/CP2019-2-2

Article 3:

Serious games going beyond the Call of Duty: Impact of an advertising literacy mini-game platform on adolescents' motivational outcomes through user experiences and learning outcomes

Steffi De Jans, Liselot Hudders, Laura Herrewijn, Klara van Geit, and Veroline Cauberghe https://dx.doi.org/10.5817/CP2019-2-3

Article 4:

Discourse analysis of online product reviews: A discussion of digital consumerism and culture Haseon Park and Joonghwa Lee

https://doi.org/10.5817/CP2019-2-4

\section{About the Journal}

The Cyberpsychology: Journal of Psychosocial Research on Cyberspace is a web-based, peer-reviewed scholarly journal. The first peer-reviewed issue was published in September 2007. The journal is focused on social science research about cyberspace. It brings psychosocial reflections of the impact of the Internet on people and society. The journal is interdisciplinary, publishing works written by scholars of psychology, media studies, communication science, sociology, political science, nursing, ICT security, organizational psychology and also other disciplines with relevance to psychosocial aspects of cyberspace. The journal accepts original research articles, as well as theoretical studies and research meta-analyses. Proposals for special issues are also welcomed.

The journal is indexed with Web of Science (Social Science Citation Index and Current Contents - Social \& Behavioral Sciences), SCOPUS, ERIH PLUS, EBSCO Academic Search Complete, the Directory of Open Access Journals and the Czech Database of Scientific Journals. 
The articles in Cyberpsychology: Journal of Psychosocial Research on Cyberspace are open access articles licensed under the terms of the Creative Commons Attribution Non-Commercial License which permits unrestricted, noncommercial use, distribution and reproduction in any medium, provided the work is properly cited.

\section{Publication Ethics and Publication Malpractice Statement}

Cyberpsychology: Journal of Psychosocial Research on Cyberspace follows the standard for Ethics and Publication Malpractice set by the Committee on Publication Ethics (COPE). Authors, reviewers, editors, and publisher are expected to conform to these standards.

\section{Editor}

Prof. David Smahel, M.Sc. et Ph.D., Faculty of Social Studies, Masaryk University, Czech Republic

E-mail: smahel(at)fss.muni.cz

\section{Associate Editors}

Prof. Kristian Daneback, Ph.D., University of Gothenburg, Sweden

E-mail: kristian.daneback(at)socwork.gu.se

Prof. Michel Walrave, Ph.D., University of Antwerp, Belgium

E-mail: michel.walrave(at)uantwerpen.be

Assist. Prof. Alexander Schouten, Ph.D., Tilburg University, Netherlands

E-mail: a.p.schouten(at)tilburguniversity.edu

Lenka Dedkova, Ph.D., Masaryk University, Czech Republic

E-mail: Idedkova(at)fss.muni.cz

\section{Managing Editor}

Lenka Dedkova, Ph.D., Faculty of Social Studies, Masaryk University, Czech Republic

E-mail: Idedkova(at)fss.muni.cz

\section{Editorial Assistant}

Marie Bedrošová, M.A. \& M.A., Masaryk University, Czech Republic

E-mail: marie.bedrosova(at)mail.muni.cz

\section{Guest Editors of Special Issue "Digital Advertising and Consumer Empowerment"}

Assist. Prof. Liselot Hudders, Ph.D., Post-Doctoral Fellow FWO, Ghent University, Belgium

E-mail: liselot.hudders(at)ugent.be

Eva A. van Reijmersdal, Ph.D., University of Amsterdam, Netherlands

E-mail: e.a.vanreijmersdal(at)uva.nl

Prof. Karolien Poels, Ph.D., University of Antwerp, Belgium

E-mail: karolien.poels(at)uantwerpen.be 


\section{Editorial Board}

Prof. Jochen Peter, Ph.D., University of Amsterdam, Netherlands

Prof. Veronika Kalmus, Ph.D., University of Tartu, Estonia

Prof. Gustavo S. Mesch, Ph.D., University of Haifa, Israel

Prof. Kaveri Subrahmanyam, Ph.D., California State University, Los Angeles, USA

Prof. Herbert Hrachovec, Ph.D., University of Vienna, Austria

Prof. Dr. Micheline Frenette, Universite de Montreal, Canada

Prof. Alexander E. Voiskounsky, Ph.D., Lomonosov Moscow State University, Russia

Prof. Michael W. Ross, Ph.D., DrMedSc, MPH, MPHEd, University of Texas, Houston, USA

Prof. Olle Findahl, World Internet Institute, Sweden

Prof. Joshua Fogel, Ph.D., Brooklyn College of the City University of New York, USA

Prof. Lelia Green, Ph.D., Edith Cowan University, Australia

Prof. Andra Siibak, Ph.D., University of Tartu, Estonia

Hana Machackova, Ph.D., Masaryk University, Czech Republic

Michelle Wright, Ph.D., Pennsylvania State University, USA

Václav Štětka, Ph.D., Loughborough University, United Kingdom

Adjunct Prof. Birgit U. Stetina, Ph.D., University of Vienna, Austria

Anna Sevcikova, Ph.D., Masaryk University, Czech Republic

\section{Advisory Board}

Prof. Bente Traen, Ph.D., University of Oslo, Norway

Prof. Charles Ess, Ph.D., University of Oslo, Norway

Prof. Dr. Ilse Kryspin-Exner, University of Vienna, Austria

Prof. PhDr. Jan Jirák, Ph.D., Charles University, Czech Republic

Prof. Vasja Vehovar, Ph.D., University of Ljubljana, Slovenia

Prof. Larry D. Rosen, Ph.D., California State University, USA

Prof. Patricia M. Greenfield, Ph.D., University of California, USA

Prof. Peter K Smith, University of London, England

Prof. Petr Macek, CSc., Masaryk University, Czech Republic

Prof. Nicola Döring, Ilmenau University of Technology, Germany

Prof. Kimberly Young, Ph.D., St. Bonaventure University, USA

Prof. Jos de Haan, Ph.D., Erasmus University, Netherlands

Prof. Monica Whitty, Ph.D., The University of Melbourne, Australia \& The University of Warwick, UK

Prof. Alistair Duff, Ph.D., Edinburgh Napier University, Scotland

Assoc. Prof. Alfred Choi, Ph.D., Nanyang Technological University, Singapore

Prof. Thurasamy Ramayah, Universiti Sains Malaysia, Malaysia

Assoc. Prof. Neil Coulson, Ph.D., The University of Nottingham, UK

Assoc. Prof. Kenneth C. C. Yang, Ph.D., University of Texas at El Paso, USA

Assoc. Prof. Sun Sun Lim, Ph.D., National University of Singapore, Singapore

Prof. Sameer Hinduja, Ph.D., Florida Atlantic University, USA

Assoc. Prof. Jana Horáková, Ph.D., Masaryk University, Czech Republic

Assoc. Prof. Radim Polčák, Ph.D., Masaryk University, Czech Republic

Assoc. Prof. Pille Pruulmann-Vengerfeldt, Ph.D., University of Tartu, Estonia

Assist. Prof. Alexander Schouten, Ph.D., Tilburg University, Netherlands

Assist. Prof. Ewa S. Callahan, Ph.D., Quinnipiac University, USA

Assist. Prof. Regina van den Eijnden, Ph.D., Utrecht University, Netherlands

Assist. Prof. Veysel Demirer, Ph.D., Süleyman Demirel Üniversitesi, Turkey

PhDr. Ing. Petr Soukup, Charles University, Czech Republic

Janis Wolak, Ph.D., University of New Hampshire, USA

Francesca Romana Seganti, Ph.D., Sapienza University of Rome, Italy

Jeff Gavin, Ph.D., University of Bath, UK

Michael Fenichel, Ph.D., New York, USA 
Leslie Haddon, Ph.D., London School of Economics, UK

Fabio Sticca, Ph.D., Marie Meierhofer Institut für das Kind, Zürich, Switzerland

\section{Publisher}

Masaryk University, Faculty of Social Studies

Jostova 10, 60200 Brno

Czech Republic

\section{Publication Schedule}

Four issues per year: two regular issues (in July and December) plus two special issues (between regular issues).

\section{About Guest Editors}

Liselot Hudders is an assistant professor and post-doctoral fellow of FWO, affiliated to the departments of Communication Sciences and Marketing at Ghent University, Belgium. She leads the Center for Persuasive Communication (CEPEC) in which a team of 25 researchers conduct research on the effectiveness of persuasive communication, both in a profit and nonprofit context. Her research focuses on how children and adults cope with digital advertising and how the new media environment affects advertising processing. In addition, she examines how consumers can be persuaded to make more sustainable choices and how this may affect their wellbeing. She has published in a wide range of SSCI-ranked journals and is a board member of the European Advertising Association and the persuasive division of $\mathrm{NefCa}$ (Netherlands-Flanders Communication Association).

Eva van Reijmersdal is an associate professor of Persuasive Communication at the Amsterdam School of Communication Research, ASCoR, University of Amsterdam, The Netherlands. Her research focuses on the effects of various forms of embedded advertising, including advergames, influencer marketing, and brand placements. Recently, she received an ASPASIA grant from the Dutch Science Foundation (NWO) for a five-year research project on the impact of disclosing the persuasive nature of embedded advertising on persuasion knowledge and persuasion among adults and children. She has published in a wide range of SSCl-ranked journals, including Journal of Youth and Adolescents, Computers in Human Behavior, Journal of Interactive Marketing, International Journal of Advertising and American Behavioral Scientist. Van Reijmersdal is an Associate Editor of the International Journal of Advertising and former board member of NeFCA's Persuasive Communication Division.

Karolien Poels is a full professor of Strategic Communication at the Department of Communication Studies, University of Antwerp, Belgium. She is a faculty member of the research group MIOS (Media \& ICT in Organizations \& Society). Starting in the field of advertising research and emotions, her research has developed in wider, mainly ICT areas such as social media, digital games and online advertising. She studies how individuals use and experience ICT and how these insights can be applied for persuasive communication (advertising, health promotion, crisis communication, consumer protection and empowerment). She is the vice-president of NeFCA (Netherlands-Flanders Communication Association: http://www.nefca.eu/), and board member of their Persuasive Communication division. 